the Internet (see S. Harnad, Nature 410, 1024-1025; 2001), and journals can increase their impact factors by publishing their contents electronically (see M. Curti, V. Pistotti, G. Gabutti \& C. Klersy, Haematologica 86, 1015-1020; 2001).

However, two shortcomings still stand out. First, online publication involves substantial costs (software development, hosting support, and so on), despite potential price cuts associated with the reduction of print editions. Second, free online access to local journals does not necessarily lead to increasing readership without a powerful means of dissemination. For these journals to be internationally recognized, regional networks with speedy access from search engines, portals and indexing services are required.

Such a network was launched in 1997: SciELO (Scientific Electronic Library Online: www.scielo.org) is a publicly funded initiative set up to promote cooperative, free electronic publishing of scientific journals from developing countries; the development of regional databases; and the implementation of indicators of scientific literature usage. It currently comprises 93 journals from Brazil, Chile and Cuba. We assessed its international impact by comparing the impact factors of journals before and after being incorporated in SciELO.

We found five Brazilian journals that had been indexed by ISI for at least five years and available in SciELO for at least two. The impact factors of these journals more than doubled (132.7\% increase, onetailed Wilcoxon signed ranks test, $P<0.02$ ) since their inclusion in SciELO.

This indicates that such networks not only foster the availability of scientific information on a regional scale, but also generate international impact which may entice researchers into publishing in the journals concerned. Those who fund and promote regionally coordinated networks for scientific electronic publishing can help developing countries to revitalize their local journals and enhance the international representation of locally generated knowledge.

Wladimir J. Alonso, Esteban FernándezJuricic

Department of Zoology, University of Oxford, Oxford OX1 3PS, UK

\section{Laboratories' gravy train has ground to a halt}

Sir - Your Opinion article "Time to halt the gravy train" (Nature 414, 829; 2001) questions the salary and benefits packages paid by international laboratories. It is entirely correct that these should be scrutinized at a time when cost efficiency is high on the agenda of most institutions, but some of the comparisons you make are oversimplified and misleading. The reality is that the gravy train ground to a halt long ago.

In comparing CERN (the European laboratory for particle physics) with DESY, Germany's main high-energy physics laboratory, which is in Hamburg, for example, you fail to take into account the significant cost-of-living differentials between Geneva and most other European locations.

As you rightly point out, CERN conducts regular tracking studies which compare our salary and benefits packages with industry and other institutions that compete for the scientific, engineering, IT and other skills we need. In this context, CERN is primarily a provider of research infrastructure, supporting a user community of more than 6,000 scientists — only 90 of our 2,700 current staff are engaged in fundamental research. We are far from topping the compensation table: indeed, in some skills areas we find it increasingly difficult to attract suitably qualified people away from their home markets, particularly in northern Europe.

As your leader implied, multinational institutions must be increasingly efficient in managing their resources and in being able to justify the investments they make. Maintaining the skills levels and human vitality of CERN is fundamental to being able to fulfil its mission as one of the world's leading scientific research establishments. In my view, the budgetary pressures we and many comparable institutions face are such that one of our biggest challenges will be to remain competitive in this respect.

Luciano Maiani

Director general, CERN, CH-1211, Geneva 23, Switzerland

\section{Tax-free pay lets funders evade responsibilities}

Sir - Although I agree with your Opinion article (Nature 414, 829; 2001) that the tax-free salary status of a few scientific researchers in Europe is an anachronism, I dispute your use of the phrase "gravy train”. Many life-science researchers are paid apparently generous tax-free stipends at some point in their careers, but these salaries are less generous after making reasonable provision for healthcare and retirement. Until Europe-wide agreements on these standard employment benefits have been reached, the alleged "gravy train" will continue.

You do not mention that government organizations such as the Max Planck

Society in Germany often pay postdoctoral researchers tax-free stipends that can hardly be described as generous between 17,850 euros (US\$15,344) and 22,000 euros a year, depending on the exact circumstances. After private healthcare (about 2,500 euros a year) and a basic pension (about 2,000 euros) have been deducted, this is not a great deal of money.

This practice should be stamped out. Surely scientists deserve the same pay and working conditions as other professionals? The era of the tax-free stipend is indeed over, but for very different reasons from the ones you suggest.

It is easy to print melodramatic headlines about the high tax-free salaries of a few physicists at CERN and to overlook the real problems faced by many more scientists around Europe. Tax-free stipends are simply a way that scientific institutions and funding bodies escape responsibilities to their employees.

\section{Francis Barr}

Department of Cell Biology, Max Planck

Institute of Biochemistry, Am Klopferspitz 18a, Martinsried 82152, Germany

\section{People, payments and positions at DESY}

Sir - In your Opinion article about benefits for scientists working abroad (Nature 414, 829; 2001) you state that only one-third of the scientists at DESY (Germany's high-energy accelerator centre) are German.

This is correct for the scientists who visit DESY to perform experiments as members of one of the four HERA collaborations or in the Synchrotron Radiation Laboratory HASYLAB. They are, however, not employed by DESY. Of the scientists on the DESY payroll, 75.4\% are German.

You also state that at DESY a young, unmarried graduate can expect to earn 18,500 euros (US\$16,346) a year. That figure is incorrect. The correct amount is 40,000 euros.

Petra Folkerts

DESY, Notkestrasse 85, D - 22607 Hamburg, Germany

The "young, unmarried graduate" positions discussed in the Opinion article referred to $\mathrm{PhD}$ students, who in Germany are usually paid a half-salary, which is typically 18,500 euros. People earning the full-time salary of around 40,000 euros cannot study for a PhD. Editor, Correspondence. 